\title{
Comparison of colposcopic directed biopsy and cytology in screening of pre invasive lesions and early detection of Cervical Cancer
}

\author{
A. Vijay ${ }^{1}$, Nath $\mathrm{JD}^{2}$, Deka $\mathrm{N}^{3}$ \\ ${ }^{1}$ Dr. A. Vijay, Post graduate student, Dept of Obstetrics and Gynecology, ${ }^{2}$ Dr J.D.Nath , Associate professor, Dept of \\ Obstetrics and Gynecology, ${ }^{3}$ Dr.N.Deka, Assistant professor, Dept of Obstetrics and Gynecology, All are affiliated to Gauhati \\ Medical College and Hospital, Guwahati, Assam, India
}

Address for correspondence: Dr A Vijay, Email: jyandip1961@gmail.com

\begin{abstract}
Introduction: Cancer cervix is the most common malignancy in the developing world and second most common in the world amongst women. The easy accessibility of cervix with newer screening and diagnostic procedures has rendered it a preventable disease. Colposcopic evaluation and guided biopsy is an important diagnostic step and standard of management for abnormal cytological smear. Methods: A cross sectional study of a total of 50 patients attending gynecology OPD in Gauhati Medical College and Hospital was conducted between July 2013 \& June 2014. Patients between 20-60 years were included. PAP smear, Colposcopy and Colposcopic directed Biopsy were taken from the suspicious areas. Results: On cytology $24 \%$ cases (12/50) were neoplastic. On colposcopy $28 \%$ cases (14/50) were neoplastic though on histopathology $50 \%$ cases $(25 / 50)$ were neoplastic. Sensitivity, specificity, positive predictive value and negative predictive value for PAP smear was $24 \%, 76 \%, 50 \%$ and $50 \%$ respectively. Sensitivity, specificity, positive predictive value and negative predictive value for colposcopy was 40\%, 84\%, 71\% and 58\% respectively. Conclusion: For screening and detection of cervical lesions combination of various methods should be employed which will increase diagnostic accuracy.
\end{abstract}

Key words: Cervical cancer, Pap Smear, Colposcopy, Biopsy, pre-invasive lesion.

\section{Introduction}

Cervical cancer has surpassed incidence of all the other cancers globally. The toll of death reaches $2,86,823$ amongst the 5,50,700 cases identified every year. In India cancer cervix remains the most common $(80 \%)$ cancer of all the genital tract malignancies accounting for onefourth of the burden of the world [1]. According to Indian Council of Medical Research (ICMR), in the Hospital Based Cancer Registries (HBCRs), Dibrugarh is the third leading site in India [2]. The report of the North Eastern Population Based Cancer Registries (PBCRs) indicates an age Standardized Incidence Rates (AIR) of 25.4 per 100,000 in Aizawal district of Mizoram state followed by AIRs in Imphal West District (20.5) and Kamrup Urban District (17.3) [3].

Dr. Papanicolaou, in his paper, New Cancer Diagnosis in Jan 1928, recognized the importance of wet fixation of cytological specimen [4]. In 1927-28 Dr. Aurel described appearance of cells of squamous cell carcinoma in scrapings from uterine cervix [5]. Since then PAP smear has become the best modality for screening of cancer cervix worldwide. It has got certain limitations such as low sensitivity (19-51\%), high false negative rate (49-

Manuscript received: $22^{\text {nd }}$ Jan 2015

Reviewed: $27^{\text {th }}$ Jan 2015

Author Corrected: $7^{\text {th }}$ Feb 2015

Accepted for Publication: 26 ${ }^{\text {th }}$ Feb 2015
$71 \%) \&$ an expert cytopathologist is required for interpretation of the results. It becomes important to use an adjunctive screening method like Colposcopy which has high sensitivity (40-85\%). It further helps to execute guided biopsies which serve as the gold standard in detecting pre invasive and invasive lesions of cervix. Present study is undertaken to screen high risk population with abnormal cytology and subjecting them to colposcopy and directed biopsies so that adequate and timely intervention can be instituted.

\section{Aims and Objectives}

- To screen high risk patients coming to gynecology OPD at the age of 20-60 years by performing Pap smear.

- To screen those high risk cases further by doing colposcopy.

- To detect all the cases of cervical intraepithelial neoplasia(CIN) and early cases of cancer cervix using colposcopy directed biopsy.

- To find out the correlation between colposcopy and pap smear findings and to take necessary steps for further management. 
- To critically evaluate the sensitivity and specificity of colposcopy versus pap smear in the screening and early detetction of cancer cervix.

\section{Methods and Materials}

A cross sectional study was conducted in the department of Obstetrics and Gynecology, Gauhati Medical College and Hospital, Guwahati from July 2013- to June2014 on patients attending Gynae OPD in the age group of 20-60 years.

\section{Inclusion Criteria}

1. Patients with symptoms like persistent vaginal discharge, post coital bleeding, post menopausal bleeding, inter menstrual bleeding, persistent leucorrhoea not responding to antibiotics

2. Normal looking cervix with symptoms or unhealthy cervix on per speculum examination.

3. Women with cervical lesions like polyps, erosion, hypertrophied cervix, cervix with nabothian cyst.

4. Women with clinical evidence of acute pelvic infection.

\section{Exclusion Criteria}

1. Women with bleeding at the time of examination.

2. Women who had been previously treated for carcinoma cervix

3. Pregnant women.

4. Women with frank lesions.

5. Women with previous cervical surgery

6. Women with normal looking cervix but asymptomatic

Patients were clinically examined after eliciting detailed history and then subjected to PAP smear and Colposcopic directed biopsy. PAP smear was obtained by using Ayre's spatula (ane cytobrush) by rotating it 360degree clockwise at the transformation zone. The scrapings were evenly distributed on a glass slide which was fixed in $95 \%$ alcohol. Interpretation of PAP smear was done by using Bethesda classification.(2001) [6].
After taking PAP smear, visualization of cervix was done by Colposcopy using normal saline, green filter, acetic acid and lugols's iodine. Results were interpreted using modified Reid's Colposcopic Index [7]. Colposcopic directed Biopsy was obtained from acetowhite areas. Tissue obtained was fixed in formalin solution and histopathological results were noted.

\section{Statistical Analysis}

The statistical analysis was done by calculating diagnostic efficacy of each test. The sensitivity, specificity, positive predictive value (PPV), negative predictive value (NPV), false positive rate, false negative rate and accuracy were calculated for Pap smear and colposcopy comparing colposcopic directed biopsy results as gold standard.

\section{Results}

A total of 50 cases of cervical smears were studied using the Bethesda System of classification and the cytological findings were compared with the corresponding histopathological findings in all the cases.

In the present study, maximum number of cases fell in the age group of 31-40 years. CIN amongst them were $14 \%$

All the patients were married. CIN after 20 years of married life was $14 \%$. Multiparous patients (more than 1 child) had high incidence of CIN. Majority of patients had low socioeconomic status with CIN in $24 \%$ cases. Chief complaint was white discharge $(38 \%)$ with CIN in $14 \%$ cases.

Per speculum findings- maximum patients had hypertrophied cervix or cervix with erosions (62\%)

In all 50 cases, results of PAP smear, colposcopy and directed biopsy were compared. Biopsy confirmed CIN-1 lesions were $16 \%, \mathrm{CIN}-2 / 3$ lesions were $20 \%$, Squamous cell carcinoma were $12 \%$ and adenocarcinoma in $2 \%$.

Table 1: correlation of cytology with histopathology findings

\begin{tabular}{|c|c|c|c|c|c|c|c|c|c|}
\hline Cytology & Normal & Cervicitis & $\begin{array}{l}\text { CIN } \\
-1\end{array}$ & $\begin{array}{l}\text { CIN } \\
-2-3\end{array}$ & SCC & $\begin{array}{l}\text { Adeno } \\
\text { carcinoma }\end{array}$ & Metaplasia & $\begin{array}{l}\text { Leukopla } \\
\text { kia }\end{array}$ & Total \\
\hline Normal & & 1 & & 1 & & & 2 & 1 & 5 \\
\hline Inflammatory & 1 & 10 & 7 & 5 & 5 & 1 & 0 & 1 & 30 \\
\hline Ascus & & 3 & & & & & & & 3 \\
\hline LSIL & & 2 & & 2 & & & & & 4 \\
\hline HSIL & 1 & 2 & 1 & 2 & & & 1 & & 7 \\
\hline SCC & & & & & 1 & & & & 1 \\
\hline Adeno carcinoma & & & & & & 0 & & & 0 \\
\hline Total & 2 & 18 & 8 & 10 & 6 & 1 & 3 & 2 & 50 \\
\hline $\begin{array}{l}\text { Percentage of } \\
\text { cytology cases }\end{array}$ & 0.04 & 0.36 & 0.16 & 0.2 & 0.12 & 0.02 & 0.06 & 0.04 & \\
\hline
\end{tabular}




\section{Research Article}

SCC- squamous cell carcinoma. LSIL- low squamous cell carcinoma, HSIL- high squamous cell carcinoma

Retrospective analysis of biopsy confirmed cases and pap smear results were compared as shown in table-1. Results can be interpreted as:

\begin{tabular}{|l|l|l|}
\hline Diseases & Histopathology & Cytology \\
\hline CIN-1 & 8 & 2 \\
\hline CIN-2/3 & 10 & 2 \\
\hline Squamous Cell Carcinoma & 6 & 1 \\
\hline Adenocarcinoma & 1 & Nil \\
\hline
\end{tabular}

Table 2: Diagnostic efficacy of PAP smear

\begin{tabular}{|l|l|l|l|}
\hline \multirow{2}{*}{ Cytology } & \multicolumn{2}{|l|}{ HPE } & Total \\
\cline { 2 - 4 } & Neoplastic & 6 & \\
\hline Neoplastic & 6 & 19 & 12 \\
\hline Non neoplastic & 19 & 25 & 38 \\
\hline Total & 25 & 50 & \\
\hline
\end{tabular}

In present study Pap smear has 24\% Sensitivity, 76\% Specificity, 50\% positive predictive value, $50 \%$ negative predictive value and $50 \%$ accuracy in diagnosing pre malignant and malignant lesions.( CIN-1 or LSIL and CIN 2/3 or HSIL are considered premalignant )

Table 3: correlation of colposcopy and colposcopy directed biopsy (hitopathology)

\begin{tabular}{|c|c|c|c|c|c|c|c|}
\hline Colposcopy & $\begin{array}{l}\text { Normal/ } \\
\text { inflammat } \\
\text { ory }\end{array}$ & $\begin{array}{l}\text { Cervicitis/ } \\
\text { metaplasia }\end{array}$ & $\begin{array}{l}\text { CIN-1/ } \\
\text { mild } \\
\text { dyspasia }\end{array}$ & $\begin{array}{l}\text { CIN 2- } \\
\text { 3/moderat } \\
\text { e/severe } \\
\text { dysplasia }\end{array}$ & Malignant & $\begin{array}{l}\text { Leukoplak } \\
\text { ia }\end{array}$ & Total \\
\hline Normal & 1 & 3 & 1 & & & & 5 \\
\hline $\begin{array}{l}\text { Inflammation/ero } \\
\text { sions/squamous } \\
\text { metaplasia }\end{array}$ & 1 & 13 & 6 & 6 & 1 & & 27 \\
\hline $\begin{array}{l}\text { Hazy/fine } \\
\text { punctations/faint } \\
\text { aw areas }\end{array}$ & & 3 & & 3 & & & 6 \\
\hline $\begin{array}{l}\text { Dense aw/coarse } \\
\text { punctuation/mosa } \\
\text { ic pattern }\end{array}$ & & 1 & & 1 & 6 & & 8 \\
\hline Polyps & & 1 & 1 & & & & 2 \\
\hline Leucoplakia & & & & & & 2 & 2 \\
\hline Total & 2 & 21 & 8 & 10 & 7 & 2 & 50 \\
\hline
\end{tabular}

Colposcopic diagnosis of CIN-1 and above lesions was made in 14/50 cases. The results are interpreted as following:

\begin{tabular}{|l|l|}
\hline Colposcopy & Biopsy \\
\hline 6 fine AW areas & 3 cases of CIN2/3 \\
\hline 8 dense AW areas & 1 case of CIN2/3, 6 cases of malignancy \\
\hline 27 erosions & 6 cases of CIN- 1,6 cases of CIN2/3, 1 case malignant \\
\hline
\end{tabular}


Table 4: Diagnostic efficacy of colposcopy

\begin{tabular}{|l|l|l|l|}
\hline \multirow{2}{*}{ Colposcopy } & HPE & Total \\
\cline { 2 - 4 } & Positive (+) & Negative (-) & \\
\hline Positive (+) & 10 & 4 & 14 \\
\hline Negative (-) & 15 & 21 & 36 \\
\hline Total & 25 & 25 & 50 \\
\hline
\end{tabular}

In the present study colposcopy has $40 \%$ Sensitivity, $84 \%$ Specificity, $71 \%$ positive predictive value, $58 \%$ negative predictive value and $62 \%$ accuracy. (Fine Acetowhite areas on colposcopy indicate CIN-1 or LSIL. Dense Acetowhite areas on colposcopy indicate CIN-2/3 or HSIL.)

\section{Discussion}

Globally cancer cervix accounts for the second most common type of cancer in the world. The high incidence of cancer cervix is attributed to lack of awareness of the disease amongst the people due to their education status (most of them are illiterate) and low socio economic status [8]. The blessing in disguise for this slow progressive disease lies in the fact that it has got a long pre invasive period and if detected early in this phase, will bring down the incidence of CIN and frank cancer cervix.

Effective screening programme at the grass root level should begin as Pap smear and pap positive and all high risk patients should be further evaluated with colposcopy and directed biopsies. Pap along with colposcopy can detect the lesions early in its pre invasive phase and can prevent deadly consequences [9].

The mean age in the present study was 37 years which is comparable to other studies [8,10,11]. Mean age in other studies were slightly lower i.e. Tuon FF et al (30.2years) \& Vaishali et al $(32.6 y e a r s) ~[12,13]$. Higher mean age group was seen in Karimi Zarchi study (42.9years) [14].

In the present study, maximum numbers of CIN cases were illiterate (64\%). Once duration of marriage increases the risk of sexual exposure increases many folds and this leads to development of dysplasias contributing to premalignant and malignant conditions of the cervix. In the present study maximum number (20\%) of CIN cases were married for 20 years or more. Saha Thapa showed mean age of marriage was 21 years [8]. Ashmita et al showed higher prevalence of CIN in cases of early marriage <18years) [15]. Increasing the number of sexual partners has the effect on increasing incidence of CIN and invasive diseases.

In the present study it was found that cases of CIN were high with the increasing parity $(>2)$. With repeated pregnancies and trauma of cervical dilatation the connective tissue of cervical epithelium become less effective in preventing cancer cell invasion. Higher parity means more number of coitus starting at young age predisposing to CIN and carcinoma cervix. In studies conducted by S Sharma et al [10] Ashmita et al [15], Malur et al [9] as well as present study pre inavasive lesions were seen in women having more than 2 children.

Socioeconomic status has always played a major epidemiological role in the genesis of dysplasia. The factors contributing to higher incidence are poor personal hygiene, poor living conditions, unstable marriages, lack of awareness and early age at first sexual intercourse. In the present study, majority of CIN cases belonged to low socio economic status which is comparable to studies conducted by Saha Thapa et al [8] \& El Moss et al [16].

In the present study majority of cases attending OPD and those who are CIN positive have chief complaints of white discharge per vaginum. The incidence of CIN is $14 \%$ amongst patients having white discharge. In other studies conducted by Saha Thapa et al [8], Malur et al [9] and Ashmita et al [15] white discharge was the presenting complaint of the patient.

Regarding the clinical appearances of cervix, the most common finding was erosion of cervix where the squamous epithelium of ectocervix was replaced by the columnar epithelium of endocervix. Erosion was seen in $62 \%$ cases out of which $24 \%$ had CIN. 


\section{Research Article}

In our study sensitivity of Pap smear was $21 \%$ as 2 cases of LSIL were reported as inflammatory and 3 cases of HSIL were reported as 1 normal and 2 inflammatory respectively. This shows high false negative smear. Specificity of Pap is $74 \%$ showing low false positive smears in the present study.

Table 5: Comparison of different studies for Pap smear sensitivity and specificity

\begin{tabular}{|l|l|l|}
\hline Studies & Sensitivity & Specificity \\
\hline Karimi zarchi et al [14] & $51 \%$ & $66.6 \%$ \\
\hline Ashmita et al [15] & $19.5 \%$ & $83.33 \%$ \\
\hline Sukhpreet singh et al [17] & $20 \%$ & $91.25 \%$ \\
\hline Tata Memorial study [11] & $57.4 \%$ & $99.4 \%$ \\
\hline Malur et al [9] & $41.66 \%$ & $96.92 \%$ \\
\hline Present study & $24 \%$ & $76 \%$ \\
\hline
\end{tabular}

In all the studies, Pap smear as a screening test, has been found to have a low sensitivity varies between $19-57 \%$ to $57.4 \%$. The sensitivity of Pap smear has been found to be lower in developing countries because of presence of infection and inflammation.

In our study sensitivity and specificity of colposcopy was $40 \%$ and $84 \%$ respectively. Our study showed low sensitivity of colposcopy as 6 cases of CIN-1, 6 cases of CIN-2 and 1 malignant case were picked up as inflammatory or having erosions on colposcopy

Table 6: Comparison of different studies for colposcopy sensitivity and specificity

\begin{tabular}{|l|l|l|}
\hline Studies & Sensitivity & Specificity \\
\hline Karimi zarchi et al [14] & $70.9 \%$ & $44.4 \%$ \\
\hline Ashmita et al [15] & $90.24 \%$ & $72.73 \%$ \\
\hline Sukhpreet singh et al [17] & $95 \%$ & $63.75 \%$ \\
\hline Tata Memorial study [11] & $64-99 \%$ & $30-93 \%$ \\
\hline Ramesh G et al [18] & $83.33 \%$ & $46.42 \%$ \\
\hline Malur et al [9] & $80 \%$ & $81.54 \%$ \\
\hline Present study & $40 \%$ & $84 \%$ \\
\hline
\end{tabular}

Sensitivity of colposcopy was found to be $40 \%$ and specificity was $84 \%$. This showed a high sensitivity and a high specificity when compared to Pap smear. The accuracy of Pap smear and colposcopy is 54\% and 62\% respectively. Expertise and experience is necessary for proper interpretation of colposcopy. With the passage of time sensitivity of colposcopy shall increase when more training will be provided to health personals regarding colposcopy and related studies.

In our study all 50 cases were subjected to colposcopically directed biopsy after performing Pap tests and colposcopy for each patient. Majority of patients showed inflammations or erosions or metaplasia having cryptic openings or doughnut appearance on colposcopy. (54\%) . Colposcopy was able to pick $28 \%$ cases as pre malignant ( CIN) which showed hazy or dense aceto white areas or fine or coarse punctuations whereas on colposcopically directed biopsy $36 \%$ cases were picked up as CIN and $14 \%$ were malignant ( squamous cell carcinoma and adeno carcinoma)

Histopathology is considered as gold standard in our study. Sensitivity and specificity of Pap smear and colposcopy is compared to the colposcopic directed biopsy positive cases.

\begin{tabular}{|l|l|l|}
\hline Diagnostic Efficacy & Pap Smear & Colposcopy \\
\hline Sensitivity & $24 \%$ & $40 \%$ \\
\hline Specificity & $76 \%$ & $84 \%$ \\
\hline Positive predictive value & $50 \%$ & $71 \%$ \\
\hline Negative predictive value & $50 \%$ & $58 \%$ \\
\hline Percentage of false negative & $76 \%$ & $60 \%$ \\
\hline Percentage of false positive & $24 \%$ & $16 \%$ \\
\hline Accuracy & $50 \%$ & $62 \%$ \\
\hline
\end{tabular}


It is evident that although colposcopy had higher sensitivity and specificity as compared to cytology. Positive predictive value is also high for colposcopy. Hence colposcopy is useful in detecting premalignant and malignant lesions of the cervix. Colposcopy and cytology used together in patients of cervical lesions have a relatively higher chance of detecting squamous intraepithelial lesions/malignancy as compared to either procedure when performed alone. Also colposcopic directed biopsy is much more reliable in picking up true positive cases as compared to biopsy through visual inspection procedures

\section{Conclusion}

Thus colposcopy offers an excellent tool in evaluating cervical lesions. It is easy and cost effective and its importance lies in teaching, diagnosis and management of pre invasive and invasive diseases. There is a need to encourage and practice sequential use of Pap smear and colposcopy along with colposcopy directed biopsy which is the gold standard in early detection and management of Cervical Intraepithelial Neoplasm (CIN) and Cancer Cervix in all the medical colleges and institutions to prevent this disease from stepping up to number one position amongst cancers in the world.

\section{Funding: Nil \\ Conflict of interest: None initiated. \\ Permission from IRB: Yes}

\section{References}

1. Ferlay J, Shin HR, Bray F, Forman D, Mathers C and Perkin DM. GLOBOCAN 2008, Cancer Incidence and mortality worldwide: IARC cancerbase No. 10 [internet]. Lyon, France : International Agency for Research on Cancer; 2010. Available from: http//globocan.aarc.fr.

2. National Cancer Registry Programme (NCRP,ICMR). Consolidated report of hospital based cancer registries 2001-2003. Bangalore: NCP, 2007. http://www.ncrpindia.org/Annual_Reports.aspx, cited on $7^{\text {th }}$ Jan 2014

3. National Cancer Registry Programme (NCRP,ICMR). Second report of the North East population based cancer registries 2005-2006. Bnagalore: NCRP ; 2008. Available at: http://www.ncrpindia.org/Annual_Reports.aspx, cited on $7^{\text {th }}$ Jan 2014.

4. Papanicolaou GN. New cancer diagnosis proceedings of the $3^{\text {rd }}$ Race Betterment conference. Battle creek. Race Betterment Foundation 1928; 528-534.

5. Brecks JS. Novaks gynecology. Lippincots Williams and Wilkins. $13^{\text {th }}$ edition, 478.

6. Bethesda system. Berek and Novak's gynecology, 2001. 585.
7. John WS, Sankarnarayan R. Colposcopy and treatment of cervical intraepithelial neoplasia: A Beginners manual: IARC Lyon 2003; 15 and 128-129

8. Saha R, Thapa M. correlation of cervical cytology with cervical histology Kathmandu University Medical Journal. 2005; Jul- Sep Vol-3, No.3, Issue 11, 222-224

9. Malur PR, Desai BR, Dala Anita, Durdi Geeta, Sherigar Bhavana, Gupta Pallac. Sequential screening with cytology and colposcopy in detection of cervical neoplasia. Journal of South Asian Federation Of Obstetrics and Gynecology; 2009; SeptemberDecember:1(3) 45-48.

10. S Sharma, M Saini, Saini A, Bhalla AA. Colposcopic Evaluation Of Patients With Abnormal Cervical Cytology And Its Histopathological Corelation- An Original Article. The Internet Journal of Gynecology and Obstetrics 2014 Volume 18 Number1.

11. Pimple S A, Amin G, Goswami S, Shastri S S. Evaluation of colposcopy versus cytology as secondary test to triage women found positive on visual inspection test. Indian J Cancer 2010;47(3):308-313.

12. Tuon FF, Bittencourt MS, Panichi MA, Pinto AP. Sensitivity and specificity of cytology and colposcopy exams with the histological evaluation of cervical intra epithelial lesions. Rev Assoc Med Bras 2002 Apr-Jun; 48(2); 140-4

13. Jain V, Vyas AS. Cervical neoplasia cyto-histological correlation ( Bethesda System) a study of 276 cases. J Cytol Histol 2010;1:106.

14. Mojgan Karimi Zarchil, Fariba Binesh2, Zohre Kazemi3, Soraya Teimoori4, Hamid Reza Soltani4, Zohre Chiti4; value of colposcopy I the early diagnosis of cervical cancer in patients with abnormal Pap smears at Shahid Sadoughi Hospital, Yazd. Asian Pacific J Cancer Prev 2012; 12, 3439-3441

15. D Ashmita, Shakuntala P.N. Shubha R Rao, S.k. Sharma and Geetanjali S. " comparison and Correlation of Available online at: www.ijmrr.in 283 | P a g e 


\section{Research Article}

Pap smear, colposcopy and histopathology in symptomatic women and suspicious looking cervix in a tertiary hospital care center. IJHSR;2013;3(5):50-59.

16. E.L.Moss, A Moran, G Douce, J. Parkes, R.W Todd and CEW redman. Cervical cytology/ histology discrepancy: a 4 year review of patient outcome. Cytopathology. 2010 Dec;21(6):389-94. doi: 10.1111/j.1365-2303.2010.00754.x.
17. Sukhpreet L Singh, Nayana A Dastur, Murari S Nanavati: a comparison of colposcopy and pap smear: sensitivity , specificity and predictive value; www.bhj.org.in/journal/2000_4203_jul00/original_447.ht $\underline{\mathrm{m}}$.

18. Ramesh G, Sudha R, Jayashree A.K. Padmini J. colposcopic evaluation of the unhealthy cervix ; Journal of Clinical and diagnostic Research 2012 August, Vol6(6) 1026-1028.

\section{How to cite this article?}

A. Vijay, Nath JD, Deka N. Comparison of colposcopic directed biopsy and cytology in screening of pre invasive lesions and early detection of Cervical Cancer. Int J Med Res Rev 2015;3(3):278-284. doi: 10.17511/ijmrr.2015.i3.052. 